Proceedings of the 16th Czech and Slovak Conference on Magnetism, Košice, Slovakia, June 13-17, 2016

\title{
Hopkinson Effect in Soft and Hard Magnetic Ferrites
}

\author{
J. Sláma*, M. UšÁková, M. Šoka, R. Dosoudil And V. JANČÁRIK \\ Institute of Electrical Engineering, Faculty of Electrical Engineering and Information Technology, \\ Slovak University of Technology, Ilkovičova 3, 81219 Bratislava, Slovakia
}

\begin{abstract}
The dependences of the susceptibility of selected spinel and hexagonal ferrites on temperature are analyzed. The susceptibility shows a peak just below the Curie temperature $T_{\mathrm{C}}$ due to the Hopkinson effect during the heating. The appearance of this effect is associated with a transition from the region of stable magnetization state to superparamagnetic relaxations of the magnetic particles. It is in contrast to other explanations of the Hopkinson effect. These results are compared with measured particles size and with scanning electron microscope micrographs of both types of ferrites.
\end{abstract}

DOI: 10.12693/APhysPolA.131.762

PACS/topics: $75.50 . \mathrm{Gg}, 75.30 . \mathrm{Kz}, 75.30 . \mathrm{Cr}$

\section{Introduction}

The Hopkinson effect means the phenomenon that an initial susceptibility $\chi$ (permeability $\mu$ ) of a magnetic material increases with increase of temperature and exhibits a sharp maximum at temperature slightly below the Curie temperature $\left(T_{\mathrm{C}}\right)$. Thus, a peculiar susceptibility peak (maximum) is usually observed below the $T_{\mathrm{C}}$ in a thermo-magnetic curve. This effect has been observed in many soft and hard magnetic materials, in hard one with fine grain structure [1-9]. Explanation of the Hopkinson effect is based on several ideas, mainly on domainwall motion. Our experimental data demonstrate that the peaks are due to the effect of superparamagnetic relaxations of a system randomly oriented, single domain, interacting magnetic particles. The explanation of experimentally observed Hopkinson peak based on superparamagnetic state at a blocking temperature $T_{b}$ just below $T_{\mathrm{C}}$ is proposed. This peak turns out to be associated with the transition from the region of stable magnetization to superparamagnetic state with connection of drastic fall of magnetic anisotropy.

\section{Experimental results and discussion}

The samples of nanosized NiZn ferrites having a structural formula $\mathrm{Ni}_{0.33} \mathrm{Zn}_{0.67} \mathrm{Fe}_{2} \mathrm{O}_{4}$ were prepared by autocombustion method based on glycine precursor, sintered at various temperatures $T_{s}[6]$. The magnetic susceptibility $\chi$ for all $T_{s}$ were measured in alternating magnetic field of $H=421 \mathrm{~A} / \mathrm{m}$ at $920 \mathrm{~Hz}$ by means of balanced alternating current bridge method (thermomagnetic analysis). Figure 1 shows the temperature dependences of susceptibility $\chi(T)$ of $\mathrm{Ni}_{0.33} \mathrm{Zn}_{0.67} \mathrm{Fe}_{2} \mathrm{O}_{4}$ sintered at $T_{s}=750,800$, and $850^{\circ} \mathrm{C}$ during $6 \mathrm{~h}$. No other crystalline phases were detected by X-ray diffraction presented in [5], however thermomagnetic analysis (Fig. 1) suggest presence of a small amount of second phase of the samples sintered at $750^{\circ} \mathrm{C}$. The size of crystallite was changed

*corresponding author; e-mail: jozef.slama@stuba.sk from about $95.9 \mathrm{~nm}$ to $157 \mathrm{~nm}$ within the given temperature range (Table I). Dependences of the average size of crystallites $D$ and the $T_{\mathrm{C}}$ on the sintering temperature are given there. $T_{C}$ of samples was determined from the $\chi(T)$ dependences. It can be concluded from all curves that the low-temperature susceptibility $\chi$ increases with temperature $T_{s}$, and the samples with higher grain-size have higher value of $\chi$. It is due to the particles size rise with $T_{s}$ and the samples with higher particles size have higher susceptibility value according to D-law. All $\chi(T)$ curves exhibit sharp pronounced Hopkinson peaks just below $T_{\mathrm{C}}$ in Fig. 1. At increase of $T_{s}$, the Hopkinson peaks become higher, which is an evidence of particle growth in Table I.

All samples with presented $\chi(T)$ in Fig. 1 are small enough to be single-domain particles, see Table I.

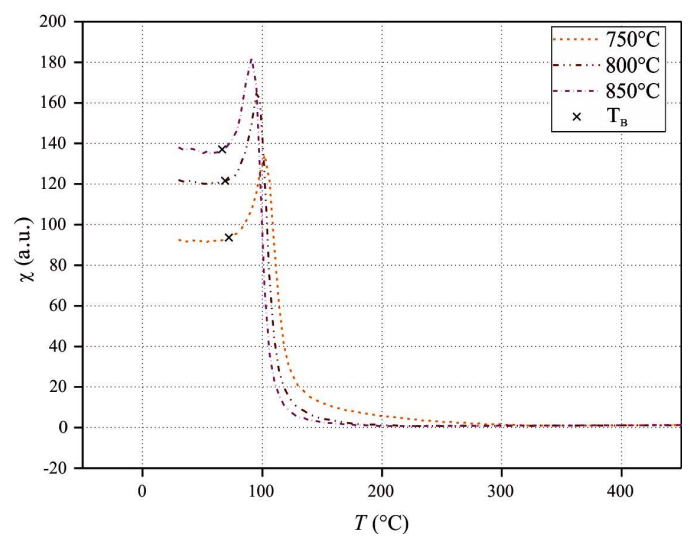

Fig. 1. Temperature dependences of the susceptibility of soft magnetic $\mathrm{Ni}_{0.33} \mathrm{Zn}_{0.67} \mathrm{Fe}_{2} \mathrm{O}_{4}$ ferrite for $T_{s}=750$, 800 , and $850^{\circ} \mathrm{C}$.

TABLE I

Size of crystallines $D$ and Curie temperature $T_{\mathrm{C}}$ as a function of sintering temperature $T_{s}$

\begin{tabular}{c|c|c}
\hline \hline$T_{s}\left[{ }^{\circ} \mathrm{C}\right]$ & $D[\mathrm{~nm}]$ & $T_{\mathrm{C}}\left[{ }^{\circ} \mathrm{C}\right]$ \\
\hline 750 & 95.9 & 110.5 \\
800 & 134.4 & 103.8 \\
850 & 157 & 99.1
\end{tabular}


The $K V$ ( $K$ - anisotropy constant, $V$ - volume of each particle) would become so small that energy fluctuations could overcome the anisotropy forces and spontaneously reverse the magnetization $M_{s}$ of particle from one easy direction to the other, even in the absence of an applied field $H$. Following that, the particles of the samples turn into superparamagnetic state above a blocking temperature $T_{b}$ just below $T_{\mathrm{C}}$. When an external field $H$ is applied, it will tend to align the moments of the particles, despite thermal energy and the Hopkinson peak occurs. The blocking temperature $T_{b}$ (below which the magnetization is stable) of the $\mathrm{Ni}_{0.33} \mathrm{Zn}_{0.67}$ ferrites was found slightly decreasing with increase of particles size (Fig. 1).

The other contribution to the Hopkinson effect study is as follows. $\chi(T)$ dependences of $\mathrm{Ni}_{0.396} \mathrm{Zn}_{0.804} \mathrm{Fe}_{1.8} \mathrm{O}_{4}$ ferrite samples where the ratio of divalent ions $\mathrm{Me}^{2+}$ to trivalent ions $\mathrm{Fe}^{3+}$ were 1:1.5 are in Fig. 2. The samples are taken from the same batch sintered at $850^{\circ} \mathrm{C} / 6 \mathrm{~h}$ and $1100^{\circ} \mathrm{C} / 6 \mathrm{~h} . T_{\mathrm{C}}$ of these samples were approximately $228.3^{\circ} \mathrm{C}$. SEM micrographs of both samples synthesized at $T_{s}=850{ }^{\circ} \mathrm{C}$ and $1100{ }^{\circ} \mathrm{C}$ are in Fig. 3. From both Fig. 2 and Fig. 3 one can conclude that the low temperature susceptibility $\chi$ increases with $T_{s}$ due to higher grain size. The existence of the Hopkinson effect is indicated in the sample sintered at $T_{s}=850^{\circ} \mathrm{C}$.

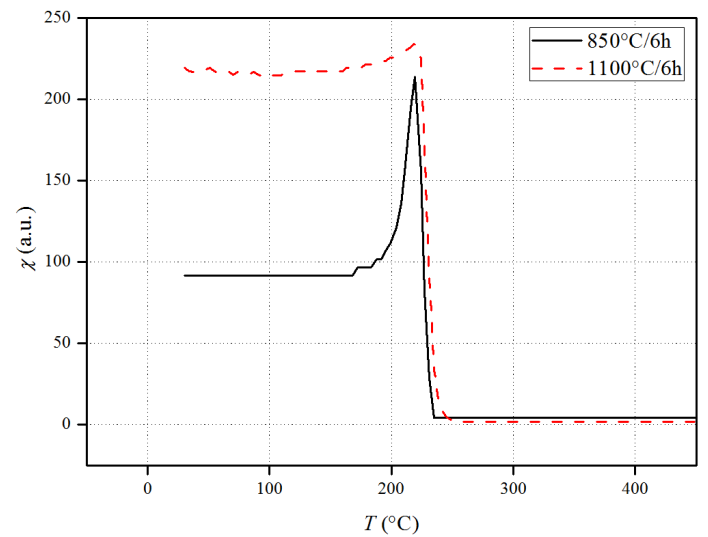

Fig. 2. Temperature dependences of the susceptibility of soft magnetic $\mathrm{Ni}_{0.396} \mathrm{Zn}_{0.804} \mathrm{Fe}_{1.8} \mathrm{O}_{4}$ ferrites.

It can be concluded that the Hopkinson peak appears in the sample sintered at $T_{s}=850^{\circ} \mathrm{C}$ because the particles size $D$ is probably lower than the upper limit $D_{P}$ of superparamagnetic state, and they are unstable at $T>T_{b}=190^{\circ} \mathrm{C}$. The main reason of the Hopkinson peak presence is again a rapid decrease of anisotropy field $H_{a}(T)=2 K / M_{S}$, yielding overcoming of the anisotropy forces by thermal energy fluctuations and spontaneous reverse of the magnetization $M_{s}$ of particles. The particles turn into a superparamagnetic state above $T_{b}$.

On the contrary, for the sample sintered at $1100^{\circ} \mathrm{C}$ a size of particles $D$ is estimated as stable one. These particles are sufficiently large $\left(D>D_{P}\right)$ so that the anisotropy is adequate and the magnetization is stable. In the sample at $T_{s}=1100^{\circ} \mathrm{C}$, all particles are larger than the critical size $D_{p}$, and the magnetization may be uniform
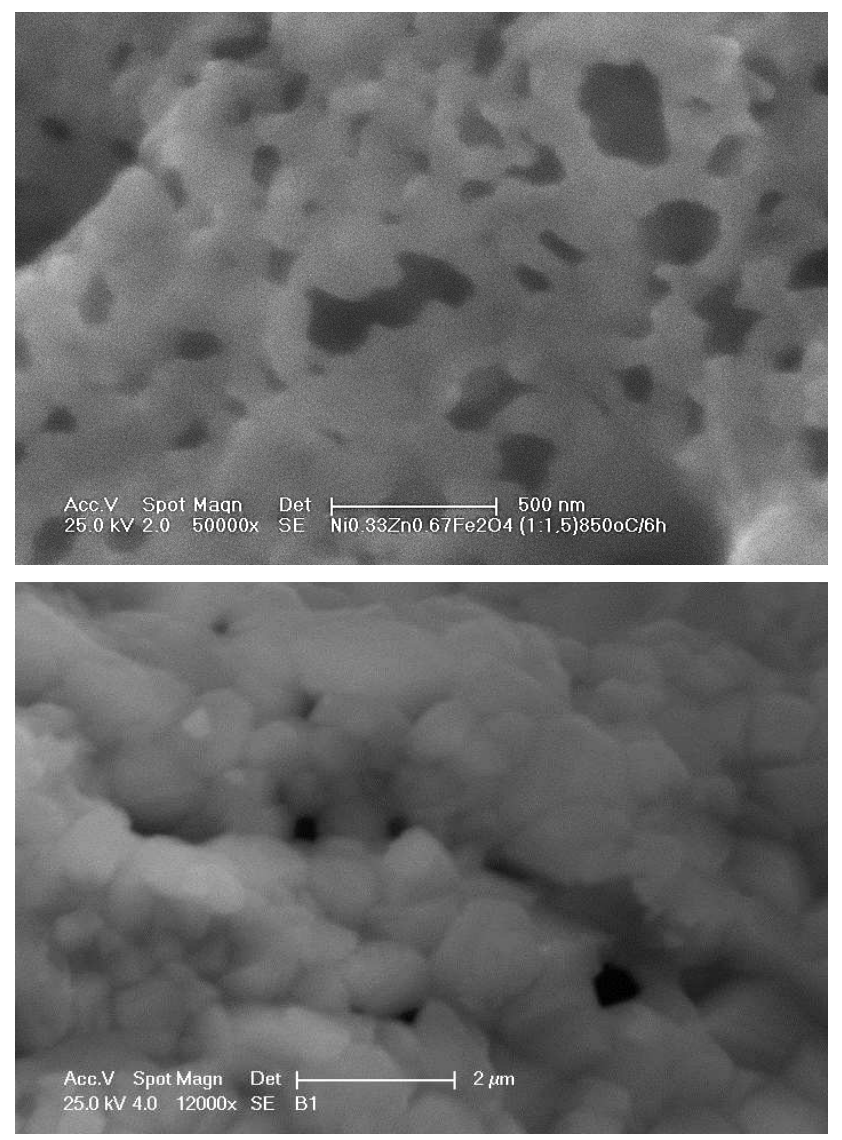

Fig. 3. SEM micrographs of $\mathrm{Ni}_{0.396} \mathrm{Zn}_{0.804} \mathrm{Fe}_{1.8} \mathrm{O}_{4}$ ferrite samples sintered at (top) $850^{\circ} \mathrm{C} / 6 \mathrm{~h}$ and (bottom) $1100{ }^{\circ} \mathrm{C} / 6 \mathrm{~h}$.

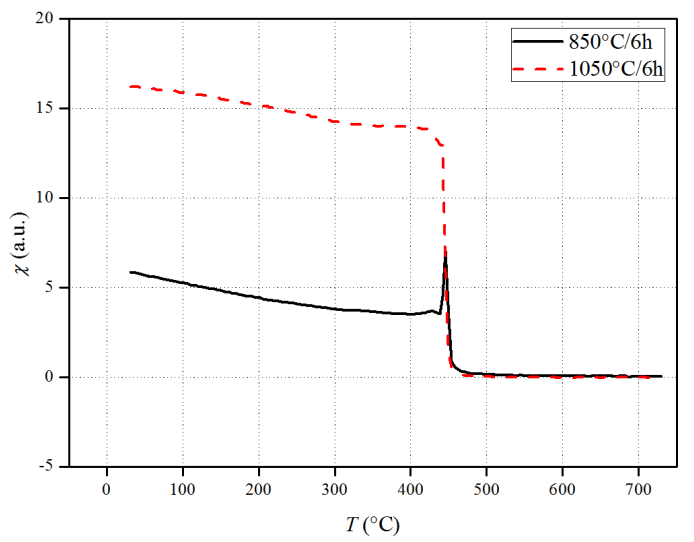

Fig. 4. Temperature dependences of hard magnetic $\mathrm{SrFe}_{12} \mathrm{O}_{19}$ ferrite sintered in $850^{\circ} \mathrm{C} / 6 \mathrm{~h}$ and $1050^{\circ} \mathrm{C} / 6 \mathrm{~h}$.

up to $T_{\mathrm{C}}$.

The next contribution to the Hopkinson effect study is as follows. $\chi(T)$ dependences of $\mathrm{SrFe}_{12} \mathrm{O}_{19}$ hexaferrite samples prepared by the combustion synthesis, and sintered at $850^{\circ} \mathrm{C} / 6 \mathrm{~h}$ and $1050^{\circ} \mathrm{C} / 6 \mathrm{~h}$ are shown in Fig. 4 . The value of $\chi$ at room temperature for sample sintered at $T_{s}=1050{ }^{\circ} \mathrm{C}$ is approximately twice than that for $T_{s}=850^{\circ} \mathrm{C}$. SEM micrographs of both these ferrite 
samples sintered at $T_{s}=850^{\circ} \mathrm{C}$ and $1050{ }^{\circ} \mathrm{C}$ are shown in Fig. 5. All particles showed nearly hexagonal platelet shape. After the temperature treatment at $850^{\circ} \mathrm{C}$, uniform particles with hexagonal structure appear, as indicated by excessive Hopkinson peak at temperature $445^{\circ} \mathrm{C}$ (Fig. 4). Such behavior is due to occurrence of the ordered single-phase structure with particles smaller than $1 \mu \mathrm{m}$.
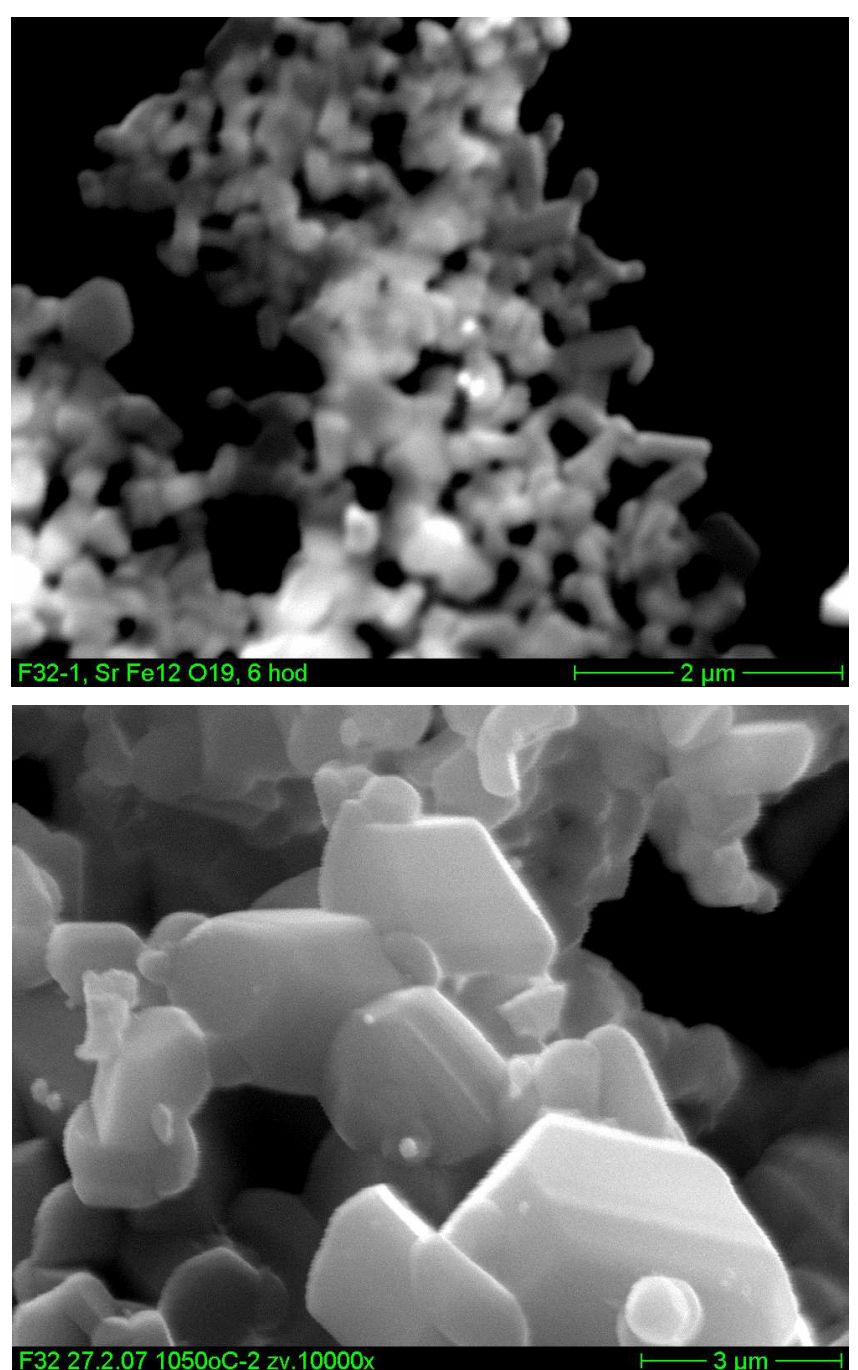

Fig. 5. SEM micrographs of $\mathrm{SrFe}_{12} \mathrm{O}_{19}$ hexaferrite samples sintered at (top) $850^{\circ} \mathrm{C} / 6 \mathrm{~h}$ and (bottom) $1050{ }^{\circ} \mathrm{C} / 6 \mathrm{~h}$.

The observation of the Hopkinson effect with associated ferrimagnetic behavior reveals mainly the single domain particle of size under critical volume. The Hopkinson peak at $\chi(T)$ curve appears as a consequence of superparamagnetic state in particles at $T>T_{b}$. We suppose that this peak can be associated with the transition from the region of stable state to superparamagnetic state of major parts of single domain grains in sintered sample. On the other hand, the $\mathrm{Sr}$ ferrite powders treated at $T_{s}=1050^{\circ} \mathrm{C}$ have larger average particle size. The corresponding $D>D_{p}$ can be estimated as roughly stable diameter. All particles are larger than the $D_{p}$, and the magnetization may be uniform (without peak) during the transitions along the easy directions up to $T_{\mathrm{C}}$.

\section{Conclusion}

The Hopkinson effect in a system of soft magnetic NiZn ferrite particles and hard magnetic Sr hexaferrites was experimentally studied. The recorded peaks on the thermomagnetic curves can be explained with the help of an approach developed for the superparamagnetic relaxation. The Hopkinson peak near $T_{\mathrm{C}}$ is related with the transition from blocked to superparamagnetic particles. The Hopkinson peak appears always close to $T_{\mathrm{C}}$ even for rather different sizes of the particles. It is because there are several materials with different value of $T_{\mathrm{C}}, M_{S}$, $H_{a}(T)$ and different value domain wall energy of grains. Then they have disparate value of size of monodomain particles, from that follows different value of their critical size. The key to understand the role of the Hopkinson peak is to recognize that particle (grain) size is smaller than the critical size at blocking temperature with the transition from the region of stable state to superparamagnetic state. Accordingly, we are led to believe that the observed Hopkinson peaks in our synthesized samples are associated with the superparamagnetic relaxations of the particles in the samples.

\section{Acknowledgments}

This work was supported by the VEGA agency of the Slovak Republic (projects no. 1/0405/16, 1/0571/15), by the University Science Park STU Bratislava (project IMTS:26240220084), and by the Slovak Research and Development Agency (contracts no. APVV-0062-11 and APVV-15-0257).

\section{References}

[1] M. Manikandan, K. Saravana Kumar, N. Aparnadevi, C. Venkateswaran, Phys. Status Solidi A 212, 2179 (2015).

[2] T. Gheiratmand, H.R. Madaah Hosseinia, P. Davami, M. Gjoka, M. Song, J. Magn. Magn. Mater. 381, $322(2015)$.

[3] V. Zhukova, M. Ipatov, A. Talaat, A. Zhukov, Phys. Status Solidi C 11, 1130 (2014).

[4] J. Slama, M. Šoka, A. Grusková, A. Gonzalez, V. Jančárik, J. Electr. Eng. 62, 239 (2011).

[5] E. Ušák, M. Šoka, M. Ušáková, E. Dobročka, Acta Phys. Pol. A 126, 68 (2014).

[6] A. Grusková, J. Sláma, M. Ušáková, M. Šoka, R. Dosoudil, J. Degmová, Acta Phys. Pol. A 118, 780 (2010).

[7] A.S. Aronin, G.E. Abrosimova, A.P. Kiselev, V. Zhukova, R. Varga, A. Zhukov, Intermetallics 43, 60 (2013).

[8] M. Manikandan, C. Venkateswaran, J. Magn. Magn. Mater. 358-359, 82 (2014).

[9] H. Pfeiffer, W. Schüppel, J. Magn. Magn. Mater. 130, 92 (1994). 